\title{
“Professor, MAS COMO É O MEU NOME EM INGLÊS?” AlguMAS REFLEXÓES E PROVOCAÇÓES SOBRE O ENSINO DE LÍNGUAS ESTRANGEIRAS EM CONTEXTO NACIONAL
}

\author{
LUIGI BARICHELLO*
}

Como é que o filhote de homem, tão frágil física e intelectualmente, tem sucesso na façanha de aprender a falar em um tempo recorde, e que lhe seja tão difícil repetir essa proeza quando, já crescido, autônomo, dotado de uma enorme quantidade de saberes e de instrumentos intelectuais, lhe acomete uma outra língua?

Christine Revuz

Mas a palavra em si mesma não vai em todos os sentidos, chocando-se sem cessar a isto: tudo náo se diz!

Jean-Claude Milner

\section{Resumo}

Nas linhas a seguir, pretendo me dirigir aos colegas professores de línguas não para apresentar respostas, mas para refletir um pouco sobre algumas perguntas e polêmicas que atravessam nossas aulas de línguas estrangeiras quase diariamente. Tomarei a liberdade de compartilhar alguns fatos de meus anos de prática docente (tanto com alunos como com professores de línguas das redes municipal e particular de ensino), tentando estabelecer um diálogo com alguns teóricos do campo do ensino e aprendizagem de línguas acerca de algumas questôes. Traçarei, também, um breve panorama do ensino de línguas estrangeiras na educação básica, arriscando levantar algumas provocaçóes e questionamentos. Apontarei, ainda, determinados aspectos dos documentos oficiais brasileiros (PCN e LDB), com vistas a perceber o respaldo legal acerca de algumas de nossas práticas, a constatação de determinadas realidades no âmbito do ensino e aprendizagem e a pertinência de certas orientaçóes que já foram outrora delimitadas por tais documentos oficiais, embora muitas apresentem mudanças ainda pouco visíveis; tanto no que diz respeito à organizaçáo escolar, quanto à produção de livros didáticos em contexto nacional.

PalaVras-Chave: Língua estrangeira, polêmicas, estranhamento, métodos, mudanças.

\section{“Teacher, but how do you say my name in English?” \\ Some considerations on the teaching of foreign languages in national context}

\section{Abstract}

In this article I present some considerations regarding teaching and learning of English as a foreign language in Brazilian context. And this is not to bring answers, but to make some important questions. At first - in order to better illustrate the considerations and criticisms

\footnotetext{
Professor de Inglês. Mestre em Linguística Aplicada pelo Instituto de Estudos da Linguagem - Unicamp, e Doutorando em Linguística pelo mesmo instituto.
} 
I intend to bring to light - I share with the readers some facts and curiosities from my ten year-experience working as a teacher and a teacher-trainer in private and public schools in Brazil. This first part of the article is a basis for the propositions I put forward regarding some changes both in the teachers' views of what a foreign language can be when subjectivity and strangeness are considered and also regarding the production of books and materials for the English language teaching-and-learning. The Brazilian legal and official documents (the "PCNs" and the "LDB") are also revisited in this article, considering some pros-and-cons of their propositions and statements, together with the expectations of students (and teachers!) towards methods, materials and books and the strangeness we face when in contact with any foreign language.

KEY wORDS: foreign language, polemics, strangeness, methods, changes.

\section{INTRODUÇÃo}

Dentre as várias perguntas dirigidas a nós, professores de línguas estrangeiras, a que escolhi para o título deste artigo me parece, sem dúvida, umas das mais comuns, e não menos intrigante. Longe de ser ingênuo ou infantil, esse questionamento nos serve como um belo exemplar para ilustrar um pouco de um sentimento muito comum quando de nosso contato com uma outra língua, sejamos crianças ou adultos: o de um inicial estranhamento.

Tomemos a pergunta ao pé-da-letra por alguns instantes. Uma resposta tradicional - e sempre à mão - caracteriza-se por contrapormos os nomes nas duas línguas: John para João, Robert para Roberto, Mary para Maria, e por aí afora... Até então, essa resposta parece satisfazer a curiosidade inicial de nossos pequenos ou já crescidos alunos - e até mesmo a nossa!

Mas... e para Rodrigo? E para Luzia? E para Renato? E o que dizer e como explicar para aquela criança que se chama Michael (pronunciado como no original ou em sua versão em português), que seu nome tem origem em outra língua (no caso, o inglês)? Percebamos que a pergunta, como dito, é intrigante, e não se encerra pela mera comparação. Há outros saberes em jogo!

Durante alguns dos meus sete anos atendendo professores das redes particular e municipal de ensino por meio de cursos de formação e aperfeiçoamento, pude notar que a pergunta dos alunos sobre o nome próprio era uma das mais relatadas pelos colegas docentes, seguida por certo descontentamento pelo fato de isso pouco ou nada aparecer nos materiais didáticos à disposição no mercado editorial nacional. Sem dúvida, é inte- 
ressante perceber aqui que essa coincidência da pergunta, em quase todo o país, nos revela que as provocaçóes levadas pela aula de língua estrangeira tocam em pontos relacionados à subjetividade, sendo a pergunta levantada pelos alunos um bom indicativo de que há um estranhamento em jogo, que não deve ser confundido, creio eu, com algo maléfico, a ser aplacado. E a pergunta, como dito, está longe de ser ingênua.

Há certamente outros ricos exemplos de questionamentos que podem registrar um pouco mais desse dito estranhamento e que nos mostram a extensão, a importância e a pertinência da aula de língua estrangeira na escola (e não me refiro aqui somente às aulas de inglês!): "É igual em Português?", “Tem palavras parecidas?", "Faz biquinho pra falar?”, "Mas tem que falar com a língua presa?", "Mas eu não sei nem português, como vou saber inglês?", "Mas eu nunca vou para os Estados Unidos, então para quê saber inglês?". O que todas essas perguntas têm em comum é tanto a marca de uma insegurança quanto a possibilidade de abertura de infinitas outras questóes, na mesma proporção em que estas forem sendo respondidas. $\mathrm{E}$ quero registrar aqui também minha posição a esse respeito: incomum seria se essas perguntas não fossem feitas!

O que isso nos aponta diz respeito à consideração, como já levantamos, da pertinência e, poderíamos dizer, do sentimento de estranhamento do falante frente a uma língua até entấo por ele desconhecida, e da iminência de um possível fracasso frente a tantas inseguranças e às mudanças e desafios do falar (ou do deixar-se falar) em outra língua. Christine Revuz (1997, p. 213), psicanalista e teórica do campo da linguagem, nos reforça essa observação com a seguinte colocação: "É preciso reconhecer: a aprendizagem de línguas estrangeiras se destaca primeiramente pela sua taxa de insucesso".

Importante aqui que destaquemos da fala da autora a consideração de que provavelmente quase todos aqueles, com raras exceçóes, que se aventurarem na experiência de tentar aprender uma outra língua apresentarão certa dificuldade, por menor que seja, e sentirão os efeitos (em diferentes medidas) do contato com essa língua outra. No contato com uma língua estrangeira muita coisa da própria língua materna será ressignificada e reconstruída. "A língua estrangeira vem incidir na relação, amplamente inconsciente, que mantemos com nossa língua fundadora", nos diz Revuz (idem, p. 220). Aqui, creio ser importante a atenção ao caráter inconsciente levantado pela autora no que diz respeito à relação que mantemos com 
nossa língua fundadora. E acredito que isso também é levado (e nos leva) para a relação com a língua estrangeira. Seria possível respondermos claramente, por exemplo, por que gostamos (ou não) de determinada língua? Ou por que esse ou aquele som de uma língua nos atrai mais que outros? Ou ainda, por que determinadas palavras nos chamam a atenção, ou por que temos maior facilidade ou dificuldade com essa ou aquela língua estrangeira? São perguntas que nos mostram um pouco da falta existente nas palavras, e como elas, ao contrário do que pensamos, não nos possibilitam dizer tudo, mesmo daquilo que nos parece táo familiar como a própria língua ou o fato de sermos falantes.

Outro exemplo que ilustra com simplicidade as relaçôes que se estabelecem entre língua materna e língua estrangeira no ambiente escolar pode ser extraído ao observarmos diversos alunos realizando hipóteses na escrita de palavras em inglês. Se foi a língua materna - em nosso caso o Português - que nos inseriu em um caminho sem volta no campo da linguagem - nos permitindo a comunicação, os desejos, os sonhos, os sentimentos e as vontades - o contato com uma língua estrangeira vem e ressignifica, de modo singular, um pouco de tudo isso. Vemos, pois, os alunos escreverem "teibou" para table, "buk" para book, etc., relutantes, muitas vezes, em tentar entender e até aceitar que há diferenças entre as línguas, até finalmente perguntarem: "por que nessa língua escrevemos de um jeito e falamos de outro?". Chegam até mesmo, como dito, a se questionar inconscientemente sobre quem são eles frente a essa nova língua, levantando a dúvida justamente acerca de seus nomes.

É comum percebermos os professores, a essa altura, se angustiarem com o fato de os aprendizes cometerem tais "incorreçóes". Todavia, essa mesma criança é aquela que escreve "pescosso" para "pescoço" ou "tambéin" para "também", por exemplo, e é a mesma que sabe dizer os nomes de todas as cores em inglês, embora tenha dificuldades na escrita dessas mesmas palavras. Essas crianças já são falantes e, por mais óbvio que isso possa parecer, é por essa razáo que elas levantam teorias, fazem perguntas e sentem-se inseguras, mas também muito dispostas a aprender a língua que se apresenta como nova. Isso nos indica que estamos aqui na ordem de algo necessário, ou seja, é preciso que as crianças passem por essas fases de questionamento, estranhamento e deslumbramento para que, pouco a pouco, comecem a se perceber enquanto falantes de uma língua, sendo que essa percepção se refina justamente no contato com uma língua estrangeira, 
seja ela qual for. Creio que, com isso, podemos perceber algo mais: que o dito estranhamento não ocorre somente nas aulas de língua estrangeira! A própria língua materna pode nos ser fonte de estranhamento (como, por exemplo, quando aprendemos a forma padrão da língua portuguesa na escola, a qual contrasta fortemente com determinados regionalismos ou idiossincrasias).

É no contato com outra língua que temos a chance de perceber minimamente o modo particular de lidarmos com nossa linguagem, com as dificuldades e facilidades que encontramos ao nos depararmos com uma língua; perceber, até mesmo, detalhes da nossa língua materna que 'não sabíamos que sabíamos'. E perceber, ainda, as sutilezas, incoerências e particularidades do nosso modo de aprender, do nosso modo de falar e de sentir, o que revela aqui, justamente, a subjetividade presente no ensino e aprendizagem de línguas, como reforçado há pouco.

Nisso residem, acredito, os pontos que dão sustentação à existência da aula de língua estrangeira no ambiente escolar: mostrar quem somos e o que somos enquanto falantes; nos arrebatar-nos pela possibilidade de não conseguirmos falar sobre algo (ou falar dele de modo ainda melhor que na língua materna!); questionar essa língua chamada de materna; trazer à consciência detalhes do nosso modo de lidar com a língua e a linguagem; mexer com músculos e partes do nosso aparelho fonador que nunca havíamos notado (justamente por não termos tido contato com uma língua que exigisse tais movimentos); perceber como outras culturas nos enxergam e como nos dirigimos a esses outros, dentre tantos outros. E ainda que isso tudo nos pareça óbvio (ou não), faz toda a diferença para crianças e adultos em fase de aprendizagem termos em mente tais consideraçóes.

Creio que seja interessante retomar aqui o fato de que o dito estranhamento nos atinge, paradoxalmente, em algo que nos parece táo particular e conhecido: a língua, a dita "nossa língua". E é a partir desse sentimento desafiador que se estruturará o começo do aprendizado de uma língua estrangeira, e é importante que, nesse caso, um velho ditado seja aplicado: o de "dar tempo ao tempo".

Propagandas e promessas de um aprendizado isento de traumas e de "qualidade garantida" em poucos meses são comuns em todas as grandes cidades, assim como materiais que primam somente por uma excelência lexical e gramatical. Não quero aqui, obviamente, questionar a validade dos métodos utilizados (e falarei sobre a questáo dos métodos logo abaixo), 
mas acredito ser importante percebermos que não estamos lidando com algo que o tempo cronológico dê conta, dada justamente a subjetividade em questáo e os apontamentos dos alunos, alguns dos quais busquei levantar até aqui. E que, portanto, não cabe às escolas, e não está ao alcance delas e de nenhum material didático (e nem ao nosso enquanto professores), ditar esse tempo de modo exato e massificado.

\section{SOBRE OS MÉTODOS DE ENSINO E O ENSINO DE INGLÊS NO BRASIL}

Atualmente, em meio aos vários métodos e abordagens a nossa disposição, é comum percebermos que diferentes discursos apontam para uma necessidade (e poderíamos até mesmo dizer uma obrigatoriedade) do aprendizado da língua inglesa, em suas mais diversas expressóes e habilidades. Postula-se que todos temos que aprendê-la, que seu aprendizado é de caráter urgente e que pode ocorrer para qualquer falante, sob pena de se ver fora das benesses e das oportunidades que um mundo considerado 'globalizado' pode oferecer caso essa injunção não seja atendida. A sobrecarga a qual nos referimos acaba sendo transformada em uma série de objetivos que devem ser cumpridos no decorrer dos anos escolares, deixando a cargo dos professores e dos alunos a tarefa de tentar dar conta da língua inglesa quase que em sua totalidade (como se isso fosse possível!), em um período de 4 a 7 anos. Nessa conjectura, todavia, dois aspectos acabam sendo descartados: a observação do já referido caráter de estranhamento dessa língua frente a nós, falantes da língua tida como materna, e seu posicionamento histórico-social.

É ponto comum tanto para nós, professores, como para os alunos, nos colocarmos em posição de alerta imediato, tendo como tarefa inicial a busca por um método que se mostre ideal e que se encaixe perfeitamente nas condiçóes existentes nas escolas e naquilo que o mercado promete (e exige). No caso de um resultado satisfatório, o método é considerado eficiente e possível de ser "aplicado", e a língua estrangeira torna-se relativamente acessível, reforçando e naturalizando as promessas feitas para a escolha deste ou daquele método. Em caso negativo, a responsabilidade recai sobre os envolvidos no processo dentro do ambiente escolar, e parte-se na busca de outro método que satisfaça o que nem mesmo os professores e os alunos parecem compreender. Cria-se, assim, um círculo vicioso, aparentemente complexo e difícil de ser rompido. 
Feita a escolha deste ou daquele método, deste ou daquele livro, é comum se imaginar que a aula de inglês possibilitará à criança ou adolescente o contato com todas as habilidades que uma língua, no caso estrangeira, poderia supostamente abranger: desde o refinamento auditivo até a fluência na fala, desde uma leitura crítica e autônoma em relação à gramática, até uma escrita espontânea e isenta de falhas. E postula-se, ainda, que o único resultado coerente e digno de ser considerado seria aquele que oferecesse ao aprendiz um domínio da língua com maestria, tal qual sua suposta relação com a língua dita materna, e nas quatro habilidades. Evidencia-se, pois, uma postura que enxerga a língua como sistema fechado, e não como discurso, fracionando-a em quatro partes e acreditando que todas elas devam ser esmiuçadas a cada nova aula, e que a soma dessas partes se traduzirá no produto final. $\mathrm{Na}$ ausência, pois, do trabalho com todas as habilidades, tende-se a desvalorizar a aula de língua estrangeira, acreditando-se que sirva somente como mais uma disciplina na grade curricular, ou um momento para a pausa da professora regente (no caso de $1^{\text {a }}$ a $4^{a}$ séries), ou de descontração e passatempo para os alunos, e que o único lugar no qual a língua inglesa pode ser apre(e)ndida é na escola de idiomas. Os parâmetros curriculares nacionais observam isso pontualmente:

A primeira observação a ser feita é que o ensino de Língua Estrangeira não é visto como elemento importante na formação do aluno [...]. Ao contrário, freqüentemente, essa disciplina não tem lugar privilegiado no currículo [...]. Tem o status de simples atividade, sem caráter de promoção ou reprovação. Em alguns estados, ainda, a Língua Estrangeira é colocada fora da grade curricular, em Centros de Línguas, fora do horário regular e fora da escola. (Brasil, 1998, p. 24)

Quero aqui fazer outra ressalva: essa aproximação/comparação da escola regular com a escola particular de idiomas é, acredito, um grande equívoco! $\mathrm{O}$ ensino de uma língua estrangeira como o inglês nas escolas de línguas não tem necessariamente as mesmas preocupaçóes educacionais para as quais a escola pública, por exemplo, está voltada. Podemos dizer, portanto, em um trocadilho que, muitas vezes, ensina-se "inglês para inglês ver", sendo que as preocupaçóes ideológicas e burocráticas acabam por prevalecer sobre as linguísticas e subjetivas, o que acaba por reforçar o paradigma de que só se aprende outra língua em centros de línguas. 
É muito comum, como dissemos, as escolas encararem o material recebido como um método - cujo resultado pode ser medido, acompanhado, esquadrinhado e aferido ao final do processo, inclusive com provas prontas - ou questionarem a que método o material pertence. Se considerarmos o material didático que escolhemos como um método ou um sistema de ensino, devemos ter em mente que cada etapa deverá ser desenvolvida em um tempo específico e rigoroso, sendo necessário seguir o livro como uma espécie de prescrição ou fórmula pronta, página a página, com limites bimestrais definidos. Será que isso é desejável quando o objeto de nosso estudo é algo tão subjetivo e infinito quanto uma língua estrangeira?

Christine Revuz (1997, p. 216) novamente nos joga um pouco mais de luz acerca dessa problemática: "Nenhum método é capaz de impedir que qualquer um que tenha o desejo de aprender uma língua estrangeira o faça”. Cabe ressaltar, de início, o caráter subjetivo por ela reforçado, que acredito não pode ser descartado quando da tentativa de transformar uma língua em objeto de estudo e recortá-la dentro de um material. Ao invés de tomarmos a fala da referida autora como uma possibilidade de se pensar um material que venha a romper com tudo o que até hoje se produziu, elaborando um outro método ou algo similar, acredito que sua contribuição nos sirva como um alerta. Um alerta para que não tomemos a questáo do "método" (ou da busca pelo melhor método) como ponto de partida ou porto de chegada, mas para que coletemos aquilo que já se produziu em termos de ensino de língua estrangeira (cientificamente e também empiricamente) e tentemos articular uma experiência de contato com o estrangeiro e o histórico nas escolas do país, e não somente com a "quantidade" linguística. Acredito que esse ponto merece atenção maior por parte de nós, professores, quando da escolha de nossos materiais e objetivos.

Outro ponto fundamental da fala de Revuz, diz respeito ao desejo, fundamental, por um lado, pois tenta levar em consideração que o aprendizado e a relação que estabelecemos com determinada língua estrangeira passará por caminhos extremamente subjetivos, não importando o método, e que o determinante não é o método, mas sim o desejo; complexo, por outro lado, pois tais caminhos não são facilmente articulados em nossa fala, ou seja, é difícil explicar e falar sobre nossas escolhas, facilidades, dificuldades e conquistas no aprendizado de uma outra língua, e por que insistimos em aprender essa ou aquela língua, e por que nos afastamos de determinadas outras, até mesmo sem conhecê-las muitas vezes. 
Os PCN, por sua vez, chegam até mesmo a trazer uma recomendação para que não se encerre um determinado material neste ou naquele método de ensino:

Em vez de se acatar imposiçóes feitas por diferentes métodos, pensa-se mais em termos de uma variedade de opçóes pedagógicas derivadas de concepçôes teóricas específicas da linguagem e da aprendizagem de línguas, além de se considerar sempre as práticas didáticas derivadas do conhecimento acumulado em relação ao ensino e a aprendizagem de Língua Estrangeira. (Brasil, 1998, p. 76)

A LDB 9394/96 também reforça essa disposição ao defender "o pluralismo de idéias e de concepções pedagógicas" (Art. $3^{\circ}$, Inciso III).

Mas é Revuz (1997, p. 216), mais uma vez, quem nos arremata essa questáo: "a multiplicação de métodos não acarretou a mesma quantidade de aprendizagens bem sucedidas. Cada um desses métodos produz seus alunos brilhantes e seus refratários".

\section{As AULAS DE INGLÊS COMO LÍNGUA ESTRANGEIRAS NO AMBIENTE ESCOLAR}

A aula dedicada ao ensino de uma língua estrangeira (e consideremos aqui não somente a língua inglesa!) existe no currículo escolar desde os tempos do Império. Naquele tempo, ensinavam-se aproximadamente cinco línguas estrangeiras, com uma carga horária muito maior do que a disponível hoje (cf. Leffa, 1999). Com o passar dos anos, o número de aulas destinado ao ensino de outras línguas foi sendo reduzido drasticamente, especialmente após a recomendação da exclusividade do inglês, em meados dos anos cinquenta. Com a grande influência da cultura estadunidense no pós-guerra - via cinema, música e comportamento - além dos pesados investimentos e do consequente endividamento do Brasil para com aquele país e para com a Inglaterra, a responsabilidade e a necessidade da aula de inglês foi ganhando espaço e status, em detrimento das demais línguas estrangeiras. Com isso, aumentaram as cobranças dos profissionais do ensino na busca por uma maneira ideal, rápida, eficiente e "não-traumática", por assim dizer, de se aprender essa língua, ao mesmo tempo em que proliferavam centenas de escolas de inglês pelo país. Pouco se observavam, por outra via, os aspectos sociais, históricos e, até mesmo, ideológicos presentes 
em seu ensino, pontos estes que merecem uma especial atenção embora sejam, atualmente, os menos trazidos para pauta nos mais diversos materiais didáticos disponíveis no mercado brasileiro.

Acerca disso, Maria José Coracini (1999, p. 106) nos expóe: "O que ainda costuma ocorrer [...] é a super-valorização do ensino e, portanto, do conteúdo (o quê se ensina) e do método (como ensinar), em detrimento da razão pela qual se aprende a língua estrangeira e da função de tal aprendizagem (para quê se aprende)".

Atenhamo-nos por alguns instantes à fala da autora no que se refere ao "para quê" por ela levantado. Costuma-se, frequentemente, como dito, repetir o discurso da incidência da língua inglesa mundo afora, o caráter irrevogável e indiscutível da globalização e do neoliberalismo, tentando-se construir ou reforçar o desejo do aprendizado da língua inglesa como língua estrangeira por essas vias, naturalizando-as. Atribui-se uma superioridade àqueles que na língua inglesa já se aventuraram, aventa-se que seus desconhecedores serão fadados aos empregos com menor remuneração e que só há espaço no mundo do trabalho, do comportamento e do consumo para quem fala inglês, como se esses vários "mundos" estivessem descolados do que chamamos de realidade (leia-se, do próprio mundo em si!). Não quero aqui me opor a uma determinada ideologia criando outra, ou seja, pensar um ensino que venha tentar derrubar ou propor uma idéia contrária a esses conceitos, em uma via tão ideológica quanto eles já se encontram, embora em uma suposta contramão. Toda proposta, independente de sua orientação ou pressupostos, já subjaz certa ideologia. "Quando um processo é denunciado como ideológico por excelência, pode-se ter certeza de que seu inverso é não menos ideológico", nos ensina o filósofo e psicanalista esloveno Slavoj Žižek (1996, p. 9). Contudo, acredito que já é tempo de se apresentar estes fenômenos e conceitos (tais como globalização, tecnologização, imperialismo, capitalismo, neoliberalismo, digitalização, virtualidade, trabalho, ideologia, biotecnologia, dentre outros) nos materiais voltados ao ensino de língua inglesa no Brasil, dada a estreita correlação entre eles e a expansão dessa língua enquanto língua franca, promovendo o que os próprios parâmetros curriculares nacionais consideram ser uma percepção histórico-social da lingua inglesa:

O uso de uma língua estrangeira é uma forma de agir no mundo para transformá-lo. A ausência dessa consciência crítica no processo de ensino e aprendizagem de inglês, no entanto, influi na manutenção do status quo ao invés de cooperar para sua transformação. (Brasil, 1998, p. 40) 
A pergunta "para quê", portanto, longe de reforçar o que hoje já se tornou lugar comum (a presença maciça da língua inglesa pelo mundo e o processo de globalização), deve tentar atender a uma possibilidade de se tentar encaminhar um pensamento histórico, crítico e socialmente constituído acerca dos motivos, fatos e acordos que levaram a língua inglesa ao seu estatuto atual, e algumas decorrências desse processo tanto para os falantes dessa língua como de outras. Acredito que as mudanças possam vir do (ou visar o) âmbito da escola regular, especialmente a pública (por exemplo, na elaboração de materiais e atividades que vislumbrem o Programa Nacional do Livro Didático, ressignificando-os e valorizando-os ainda mais): "A Língua Estrangeira no ensino fundamental tem um valioso papel construtivo como parte integrante da educaçáo formal. Envolve um complexo processo de reflexão sobre a realidade social, política e econômica [...]" (Brasil, 1998, p. 41).

Retomando a observação do ensino de inglês pelo país, o que temos hoje se resume a um ou dois encontros semanais de cinquenta minutos (para a $2^{a}$ fase do Ensino Fundamental), salas de aula numerosas (chegando a 50 ou 60 alunos/sala) e diversas cobranças, tanto por parte dos alunos quanto dos pais e, principalmente e ainda com maior ênfase, da própria escola. Os Parâmetros Curriculares Nacionais, mais uma vez, reconhecem as dificuldades, as quais não se concentram somente em regiốes afastadas dos grandes centros - estando presentes inclusive neles -, e mencionam alguns pontos que ainda devem ser considerados e que perfazem a realidade do ensino de línguas estrangeiras no Brasil:

Deve-se considerar também o fato de que as condiçóes na sala de aula da maioria das escolas brasileiras (carga horária reduzida, classes superlotadas, pouco domínio das habilidades orais por parte da maioria dos professores, material didático reduzido ao diz e livro didático, etc...) podem inviabilizar o ensino das quatro habilidades comunicativas. (Brasil, 1998, p. 21)

Ou ainda,

[...] falta de materiais adequados, classes excessivamente numerosas, número reduzido de aulas por semana, tempo insuficiente dedicado à matéria no currículo e ausência de açóes formativas contínuas junto ao corpo docente (idem, p. 25). 
Não quero me aprofundar em numerar e listar as dificuldades presentes em grande parte das escolas (especialmente as municipais) brasileiras, até porque elas já nos são bem conhecidas, entretanto, acredito que uma observação é válida: se os PCN datam do ano de 1998 (vale dizer, uma década atrás!), quais foram as modificaçóes no âmbito escolar que conquistamos de lá para cá? Quais as verdadeiras mudanças conceituais pelas quais os materiais didáticos passaram nesse período? Houve rompimentos? Não seria uma mudança conceitual um pouco mais arrojada na produção de materiais didáticos bem-vinda após uma década da edição dos parâmetros curriculares, mudança essa, inclusive, defendida por esse mesmo documento?

O que quero cercar aqui, antes do término dessas linhas, é o fato de que tais dificuldades podem ser contornadas com uma mudança nos objetivos do ensino de línguas estrangeiras em âmbito regular. Em outras palavras, creio que o caminho não seja ficarmos esperando uma mudança somente nas condiçóes de ensino e formação dos professores até que possamos pensar em dar ao ensino de línguas outro caráter. Acredito que uma mudança em nosso modo de enxergar a pertinência e o valor do aprendizado de outras línguas na escola poderá, além de até mesmo acelerar o processo de mudança, promovê-lo de modo mais igualitário e diferenciado.

É importante, acredito, considerarmos o fato de que ensinar e aprender línguas é também ensinar e aprender percepçóes da realidade e do mundo, instigando subjetividades, e isso independentemente do grau de proficiência atingido na língua. Exemplos como as perguntas das crianças sobre o nome próprio e tantas outras nos mostram que uma aula de língua estrangeira extrapola, por exemplo, um conteúdo gramatical, e que é chegada a hora, acredito, de considerarmos realmente algumas mudanças no modo como enxergamos os objetivos e prioridades dos materiais e do ensino de línguas estrangeiras nas escolas de ensino fundamental e médio do país.

\section{REFERÊNCIAS}

BRASIL. Ministério da Educação. Lei $9394 / 96$ - LDB: Lei de Diretrizes e Bases da Educação Nacional. Brasília: MEC, 1996.

BRASIL. Ministério da Educação. Secretaria de Educação Fundamental. Parâmetros Curriculares Nacionais: língua estrangeira. Brasília: MEC/SEF, 1998. 
CORACINI, M. J. Interpretação, autoria e legitimação do livro didático: língua materna e língua estrangeira. Campinas: Pontes, 1999.

LEFFA, V. J. O ensino de línguas estrangeiras no contexto nacional. Contexturas, APLIESP, n. 4, p. 13-24, 1999.

REVUZ, C. A língua estrangeira entre o desejo de um outro lugar e o risco do exílio. SIGNORINI, I. (Org.). Linguagem e identidade: Elementos para uma discussão no campo aplicado. Campinas: Mercado das Letras, 1997. p. 213-230.

ŽIŽEK, S. O espectro da ideologia. ŽIŽEK, S. (Org.). Um mapa da ideologia. Rio de Janeiro: Contraponto, 1996.

Recebido em: 20 set. 2008

Aceito em: 15 fev. 2009 